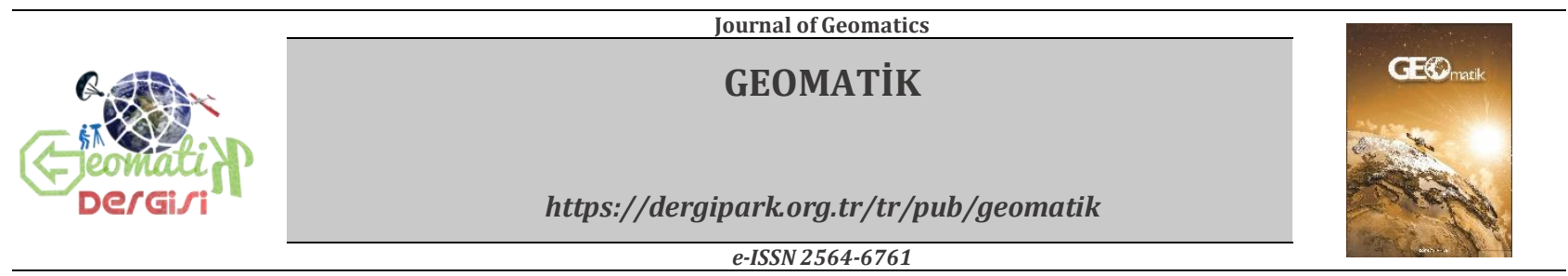

\title{
Orman meşcere yükseklik haritası üretiminde hava kaynaklı lazer tarama performans analizi
}

\author{
Umut G. Sefercik*1 ${ }^{*}$, Ayhan Ateşoğlu ${ }^{2}$, Can Atalay ${ }^{3}$, \\ ${ }^{1}$ Gebze Teknik Üniversitesi, Harita Mühendisliği Bölümü, Kocaeli, Türkiye \\ 2Bartın Üniversitesi, Orman Mühendisliği Bölümü, Bartın, Türkiye \\ ${ }^{3}$ Zonguldak Bülent Ecevit Üniversitesi, Geomatik Mühendisliği Bölümü, Zonguldak, Türkiye
}

Anahtar Kelimeler
Hava kaynaklı lazer
tarama
Orman meşcere yükseklik
haritası
DYM
DAM
NDYM

\section{ÖZ}

Orman envanterinde önemli bir parametre olan meșcere yükseklik bilgisi, az gelişmiş ya da Türkiye gibi gelișmekte olan ülkelerde halen yaygın șekilde yersel tekniklerle tekil ağaç bilgisi edinme ve hata payı oldukça yüksek kestirimler ile bu bilgiyi genele yayma prensibi ile elde edilmektedir. Uzaktan algllama (UA) temelli modern ölçüm teknolojilerinin devinimi ile Amerika ve Avrupa ülkeleri bașta olmak üzere gelișmiș ülkeler orman meşcere yükseklik belirleme çalışmalarında hata payı yüksek yersel yöntemlerin kullanımından vazgeçmişlerdir. Bu çalışma, hava kaynaklı lazer tarama (ALS) yoğun nokta bulutları ile orman meșcere yükseklik haritası üretimi ve üretilen haritanın mutlak konum doğruluğu potansiyelinin ortaya koyulmasını amaçlamaktadır. Amaç doğrultusunda, Houston, ABD'de orman-yoğun bir çalıșma alanı seçilmiș, ALS verileri ile dijital yüzey ve arazi modelleri üretilmiş ve bu ürünler temelinde normalize dijital yüzey modeli tekniği kullanılarak üç boyutlu orman meşcere yükseklik haritası elde edilmiştir. Üretilen haritanın doğruluğu, aynı çalıșma alanında yersel lazer tarama (TLS) tekniğinden elde edilen veriler ile üretilen orman meşcere yükseklik haritası kullanılarak model bazlı yaklașımlarla değerlendirilmiștir. Değerlendirmelerde, standart sapma ve normalize medyan mutlak sapma uluslararası doğruluk metrikleri kullanılmıștır. Sonuçlar ıșığında, ALS verileri ile üretilen meșcere yükseklik haritasının yatayda $\pm 1 \mathrm{~cm}$ düşeyde ise $\pm 40 \mathrm{~cm}$ dolayında mutlak konum doğruluğuna sahip olduğu tespit edilmiştir.

\section{Airborne laser scanning performance analysis in the forest stand map production}

\section{Keywords}

Airborne laser scanning

Forest stand height map

DSM

DTM

NDSM

\begin{abstract}
Stand height information, a significant parameter for forest inventory, is widely obtained with acquiring single tree information with geodetic techniques in underdeveloped or developing countries like Turkey. Acquired single tree information is generalized for whole forest stand with high error rate estimations. Developed countries, especially America and European countries, have completely excluded terrestrial methods with a high margin of error in forest stand height determination studies with the development of modern measurement technologies based on remote sensing (RS). This study aims to produce forest stand height map with airborne laser scanning (ALS) dense point clouds and to reveal the absolute location accuracy potential of the produced map. For this purpose, a forest-dominant study area was selected in Houston, USA, digital surface and terrain models were produced with ALS data, and a three-dimensional forest stand height map was obtained using a normalized digital surface model technique. The accuracy of the map produced was evaluated with model-based approaches using the forest stand height map produced with the data obtained from terrestrial laser scanning (TLS) technique in the same study area. International accuracy metrics for standard deviation and normalized median absolute deviation were used in the evaluations. In the light of the results, it has been determined that the stand height map produced with ALS data has an absolute position accuracy of $\pm 1 \mathrm{~cm}$ horizontally and $\pm 40 \mathrm{~cm}$ vertical.
\end{abstract}




\section{GíRiş}

Geçtiğimiz onyıllar içerisinde, üç boyutlu (3B) coğrafi bilgi sağlayan uzaktan alglama (UA) teknikleri, özellikle Dünya'nın yüzeyini analiz eden topoğrafik araştırmalar için vazgeçilmez hale gelmiştir. UA teknolojileri, haritacılık başta olmak üzere şehir bölge planlama, peyzaj, ormancılık, (Vatandaşlar ve Zeybek 2020), jeoloji, felaket izleme (Zeybek ve Şanlığlu 2015), arkeoloji (Şanlıŏlu ve ark. 2013), tarım, oşinografi vb. gibi bir çok disiplin tarafından yoğun şekilde tercih edilmektedir.

Orman envanter çlkarımı, ortalama meşcere yüksekliği, ağaç türleri ve bunların dağılımı ve kereste hacmi gibi tekil ağaçla ilgili parametrelere dayanan tekrarlı yapılma zorunululuğu olan ve maliyetli yersel ölçümler gerektiren bir konudur (Koch ve ark. 2006). Günümüzde, bu parametrelerin çoğuna ilişkin bilgiler, UA verileri ve $3 \mathrm{~B}$ sonuç ürünleri ile elde edilmektedir. UA'da yeryüzünün ve/veya üzerindeki nesnelerin $3 \mathrm{~B}$ betimlemesi, çıplak topoğrafya ve üzerindeki tüm doğal ve insan yapısı objelerin kuşbakışı kartoğrafik 3B sunumu olan dijital yüzey modeli (DYM) ve yalnızca çıplak topoğrafyanın 3B temsili olan dijital arazi modeli (DAM) ve dijital yükseklik modeli kavramlarıyla yapılır. Bu çalışmada, orman meşcere üst yüzeyleri DYM, orman altı çıplak topoğrafya ise DAM terimi ile tanımlanmıştır. Hava kaynaklı lazer taramadan (ALS) elde edilen yoğun nokta bulutlarından DYM ve DAM temelinde yüksek çözünürlüklü $(25 \mathrm{~cm}) 3 B$ orman meşcere haritası üretimi ve üretilen haritanın model bazlı görsel ve istatistiksel sorgulamaları ana motivasyon kaynağı olmuştur.

DYM ve DAM doğrulukları, orman envanter çalışmalarının sonuçlarını direk olarak etkilediğinden mutlaka sorgulanmalıdır. UA tekniklerinde düz ve açık alanlarda 3B modelleme potansiyeli, yüksek konum doğruluklu yersel ölçümlerden elde edilen kadar yüksektir (Birdal ve ark. 2017). Ancak, görüntüleme geometrileri ve sınırlı algılama yetenekleri nedeniyle, uzaktan algılanan veriler eğimli veya orman kaplı topoğrafyalarda 3B tasvirde doğruluk kaybına uğrarlar. Uzay kaynaklı stereo optik görüntüleme ve fotogrametriden elde edilen pasif uzaktan algılama verilerini kullanarak, 3B yeryüzü modellemesi operatöre bağlı yarı otomatik bir süreçtir. Dijital görüntüler çok yüksek mekansal ve spektral çözünürlüğe sahip olsa bile, alan ve obje tabanlı otomatik görüntü eşleștirme algoritmalarının performansı sınırlıdır ve operatör sonuç ürünlerin doğruluğunu artırmak için görsel olarak ek eşleştirme noktaları eklemelidir. Dahası, yoğun orman alanlarında, düşük optik korelasyon nedeniyle, operatörün işlevselliği daha da önemli hale gelir ve otomatik eşlemede ayrıntıların eksikliğinden dolayı operatörler, stereo model üzerinde durgun su ve yangın yolları gibi detaylardan sınırlı sayıda nokta tayini ile kot noktası üretmeye çalışırlar. Optik uydu görüntüleri üzerinde bilgi içeriği çıkarımında, yapay renk (false color) ve normalize bitki örtüsü indeksi (NDVI) gibi bant kombinasyonlarına dayanan görüntü iyileștirme yöntemleri uygulanabilmesine rağmen, 3B bilgi çıkarımında bu yöntemler yetersiz kalmaktadır.

Yapay açıklıklı radar (SAR) görüntüleri cephesinde ise, DYM'leri üretmek için tam otomatik bir süreç sunan interferometrik yapay açıklıklı radar (InSAR) teknolojisini kullanma avantajı vardır. Ancak, radarın orman penetrasyon kabiliyetine sahip uzun dalga-boylu P ve L bantları (19.3 - 133 $\mathrm{cm})$, tek ağaç tabanlı orman envanteri çalışmaları için gerekli olan mekansal çözünürlüğü $(\leq 1 \mathrm{~m})$ karşılayamamaktadır. Diğer SAR görüntüleme bantları ( $S, C$ ve $X$ gibi) ise düşük penetrasyon kabiliyetleri nedeniyle orman örtüsüne gereğince nüfuz edemez ve alttaki çıplak topoğrafya hakkında doğru ve yeterli bilgi sunmaları olanaksızdır. Bahsedilen UA teknolojilerindeki bu sınırlamalardan dolayı, hızlı elde edilebilir, yoğun ve yüksek doğruluklu 3B topoğrafik nokta bulutları sunan ALS, UA teknolojileri içinde orman alanlarının haritalanmasında temel teknik olma potansiyeline sahiptir (Baltsavias 1999, Hill ve ark. 2000, Hyyppä ve ark. 2006, Hollaus ve ark. 2007). Bilim camiası tarafından, orman penetrasyon yeteneğine sahip lazer sinyallerinden elde edilen çoklu ekoların (dönüşlerin) algılanması ile üretilen yoğun nokta bulutları DYM ve DAM'ların üretimi için etkili bir çözüm olarak düşünülmektedir ve bu konuda literatürde çok sayıda çalışma yer almaktadır (Lohr 1998, McIntosh ve ark.2000, Shan ve Sampath 2005, Mandlburger ve ark. 2007, Baligh ve ark. 2008, Liu 2008, Akay ve ark. 2012, Sefercik ve ark. 2015). ALS tekniği, hava kaynaklı lazer tarayıcı yanısıra taramanın yapıldığı anki platformun yüksek doğruluklu konum ve dönüklük bilgilerinin elde edilmesi prensibi doğrultusunda çoklu global navigasyon uydu sistemleri (GNSS) ve atalet ölçüm birimi (IMU) entegrasyonu ile çalışmaktadır (Vosselman ve Maas, 2010).

$\mathrm{Bu}$ çalışmada, Houston Üniversitesi ana kampüsünde yer alan orman-yoğun bir alanda, normalize dijital yüzey modeli (nDYM) tekniği kullanılarak 3B orman meșcere yükseklik haritası üretilmiştir. NDYM, DYM ve DAM'ın diferansiyel modelidir ve orman meşcere yüksekliklerini belirlemek için en güvenilir ve sık kullanılan tekniklerden biridir (Sterenczak ve ark. 2008, Smreček 2012). Literatürdeki birçok çalışmadan farklı olarak bu çalıșmada, yoğun ALS nokta bulutları kullanarak nDYM üretiminde en önemli ve hataya açık noktalar tespit edilmiş ve doğru bir modelin nasıl elde edileceğine dair öneriler sunulmuştur. Ayrıca, oluşturulan nDYM tabanlı haritanın doğruluğu, literatürdeki nokta bazlı değerlendirmelerin aksine, yersel lazer tarama (TLS) verisinden elde edilen referans nDYM'ye dayalı model-bazlı yaklaşım kullanılarak analiz edilmiștir. TLS, sağladığı milimetre mertebesinde hızlı ve periyodik nokta bulutları ile gelişmiş ülkelerde ormancilık envanter çalışmalarında sıç̧a tercih edilen bir yöntemdir (Liang ve ark. 2016). ALS ve TLS 
verileri literatürde ormancılık çalışmalarında çeşitli amaçlarla sıkça birlikte kullanılmışlardır. Hilker ve arkadaşları 2010 yılında yaptıkları çalıșmada orman örtüsü yüzeylerini ve yaprak alanlarını ALS ve TLS teknikleri ile ölçmüş ve kıyaslamışlardır (Hilker ve ark. 2010). Holopainen ve arkadaşları, üç ayrı test alanında manuel olarak TLS verisinden oluşturdukları orman haritalarını ALS, mobil lazer tarama (MLS) ve yine TLS verileriyle kıyaslayarak doğruluk sıralaması yapmışlardır (Holopainen ve ark. 2013). Hauglin ve arkadaşları, normalde GNSS ile tespit ettikleri orman alanlarındaki tekil ağaç konum bilgilerini TLS ve ALS ile belirlemeye çalışmış ve performans değerlendirmesi yapmışlardır (Hauglin ve ark. 2014). Ma ve arkadaşları ormandaki yaprak vb. elemanların yok olma katsayılarını inceledikleri ve orman örtüsünde radyasyonun zamansal etkisini modellemeye çalıștıkları çalışmalarında TLS ve ALS verilerinden faydalanmışlardır (Ma ve ark. 2017). Paris ve arkadaşları çalışmalarında ağaç taç yapılarını ALS ve TLS ile belirlemeye çalıșmışlardır (Paris ve ark. 2017). Bazezew 2017 yllında tamamladığı doktora tez çalışmasında yer üstü biyokütle/karbon hesaplamasinda ALS ve TLS verilerinin entegrasyonundan elde edilen orman parametrelerini kullanmıştır (Bazezew 2017).

Makale, amaçları doğrultusunda şu şekilde düzenlenmiştir: ikinci bölümde, çalışma alanı ve materyaller sunulmuştur. Üçüncü bölümde, 3B orman meşcere yükseklik haritası üretimi ve doğruluk değerlendirme metodolojisi verilmiştir. Dördüncü bölümde, üretilen harita ve doğruluk potansiyeline ilişkin bulgular sunulmuş ve takip eden beşinci bölümde tartışılmıştır. Sonuç ve öneriler bölümü ile çalışma sonlandırılmıştır.

\section{2. ÇALIŞMA ALANI VE MATERYALLER}

ABD'nin Teksas Eyaletinde bulunan Houston Üniversitesi ana kampüsünde orman-yoğun bir bölge, çalışma alanı olarak seçilmiştir. Alan, 13.000 $\mathrm{m}^{2}$ ve açık, çim ve orman olmak üzere üç farklı arazi sınıfından oluşmaktadır. Alanın ortometrik yüksekliği 10 ile $33 \mathrm{~m}$ arasında değişmektedir. Şekil 1, çalışma alanı ve içerdiği arazi sınıflarını göstermektedir.

Çalıșmada kullanılan ALS verileri, Houston Üniversitesi Hava Kaynaklı Lazer Tarama Ulusal Merkezi (NCALM) tarafından gerçekleştirilen uçuşlar neticesinde elde edilmiştir. Uçuşlar esnasında, tüm ana kampüs alanı $\left(3 \times 9 \mathrm{~km}=27 \mathrm{~km}^{2}\right)$ kaplanmış ve çok yüksek çözünürlüklü nokta bulutları, helikoptere monte edilmiş Optech Gemini hava kaynaklı lazer tarayıcı ile toplanmıştır. Nokta bulutlarının yoğunluğu nedeniyle, bilgisayar ve yazılım kapasiteleri göz önünde bulundurularak, veriler $1 \times 1$ km'lik 27 bölüme ayrılmıș ve ayrı ayrı değerlendirilmiştir. TLS ölçümleri Riegl VZ-400 cihazı ile elde edilmiştir. Ölçüm aletleri ve özellikleri Tablo 1'de sunulmuştur. Tablo.1'de görülebileceği gibi, ALS ve TLS verileri yılın aynı döneminde toplanmamıştır. Ancak, çalışma alanındaki ağaçlar canlı meșe olduğundan, tüm yıl boyunca yapraklarını korumaktadırlar. Bu nedenle yapraklı ve yapraksız verilerin toplanmasına gerek kalmamıştır.

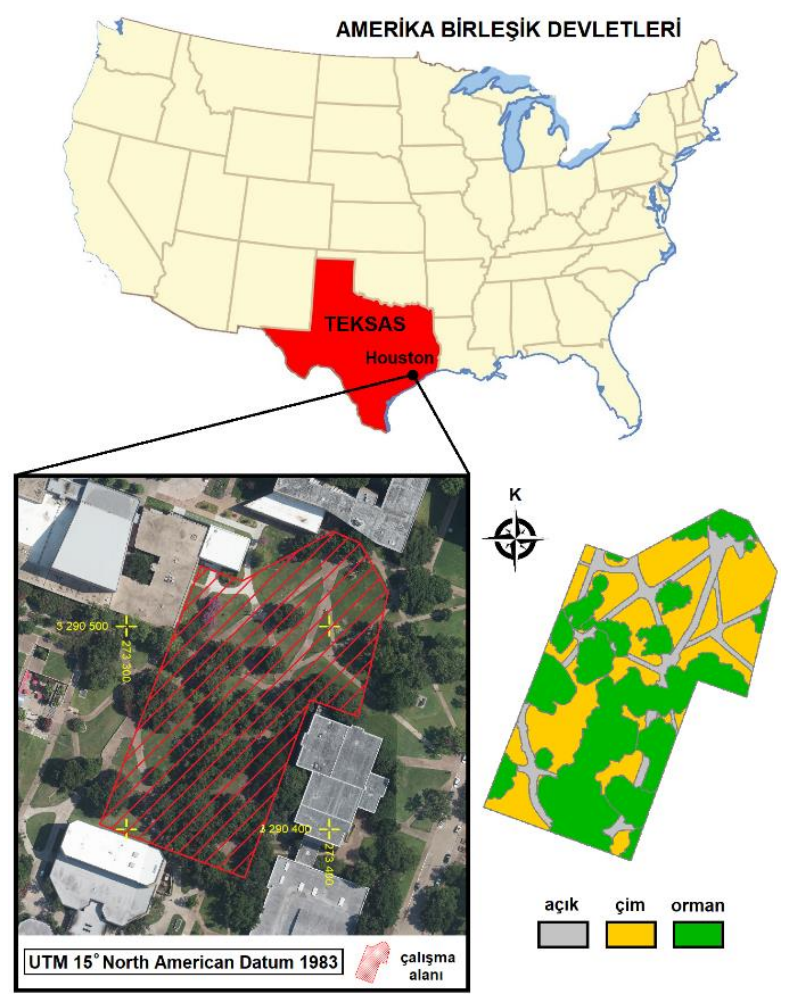

Şekil 1. Çalışma alanı ve içerdiği arazi sınıfları

Tablo 1. Kullanılan aletlerin ve ölçümlerin özellikleri

\begin{tabular}{|c|c|c|}
\hline Parametre & ALS & TLS \\
\hline Tarayıcı & $\begin{array}{c}\text { Optech } \\
\text { Gemini ALTM }\end{array}$ & Riegl VZ-400 \\
\hline $\begin{array}{l}\text { Nokta yoğunluğu } \\
\left(\mathrm{m}^{2}\right)\end{array}$ & 45 & $\begin{array}{l}\approx 10000 \leq 10 \mathrm{~m} \\
\text { yatay mesafede }\end{array}$ \\
\hline Puls oranı (kHz) & 167 & 300 \\
\hline Dalgaboyu (nm) & 1064 & 1550 \\
\hline $\begin{array}{c}\text { Tarama frekansı } \\
(\mathrm{Hz})\end{array}$ & $0-70$ & - \\
\hline $\begin{array}{l}\text { Işın genişliği } \\
\text { (mrad) }\end{array}$ & 0.25 & 0.35 \\
\hline Bakış açısı (ํ) & -25 ten +25 & $\begin{array}{c}360 \text { yatay / }-40 \\
\text { dan }+60 \text { düșey }\end{array}$ \\
\hline Sinyal dönüș sayısı & 4 & $\sim$ limitsiz \\
\hline Uçuş yüksekliği & 1000 & - \\
\hline
\end{tabular}
(m)

Veri alım tarihi

$23 / 06 / 12$

$13 / 11 / 13$

\section{3. ÜRETIM VE DEĞERLENDIRME METODOLOJÍsi}

3B orman meşcere yükseklik haritasının üretimi ve doğruluğunun değerlendirilmesi için beş adımlı bir metodoloji izlenmiştir (Şekil 2). Ham ALS verilerinin işlenebilir hale gelmesi için uçuş şeritlerinin kalibrasyon işlemi yatay ve düşey çarpraz korelasyon tekniği ile obje (genelde bina çatısı) eşleştirme bazında gerçekleşmiştir (Glennie ve ark. 2013). Çalışmada, ALS verilerini işlemek, DYM, DAM ve 3B orman meşcere haritalarını 
oluşturmak ve üretilen modellerin ve haritaların konum doğruluğunu belirlemek için Microstation Terrascan, BLUH (Bundle Block Leibniz University Hannover), Surfer ve LISA yazılımları kullanılmıștır. Koordinat sistemi ve yatay datum olarak, evrensel enlem merkatörü (UTM) $15^{\circ}$ ve Kuzey Amerika Datumu 1983 (NAD83) kullanılırken, yükseklik değerleri ortometrik uygulanmıştır.

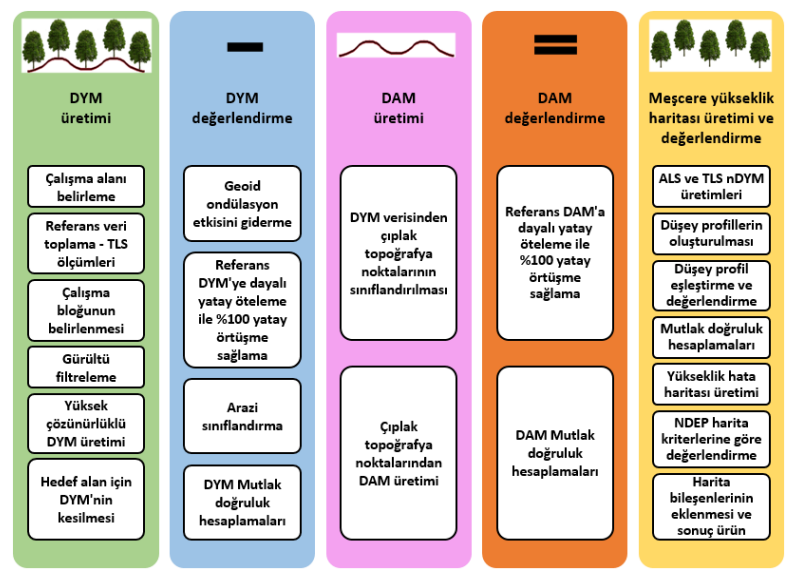

Şekil 2. 3B Meșcere yükseklik haritası üretim ve değerlendirme adımları

\subsection{DYM ve DAM üretimi}

DYM ve DAM üretimi için öncelikle çalışma alanını kapsayan bir çalışma bloğu tanımlanmıştır. Çalışma bloğu, DYM ve DAM'da enterpolasyon etkisine bağlı hatalı sınır kenar hatlarını önlemek için tüm sınır çizgileri doğrultusunca çalışma alanından daha geniș alınmıștır. Tam sınırda seçim yapılması durumu, enterpolasyon sırasında arama yarıçapında (radius) sınır hattı dışında nokta olmaması nedeniyle 3B modelin sınır hatlarının hatalı üretimi sonucunu doğurur.

ALS nokta bulutlarında meydana gelen gürültüyü ortadan kaldırmak için üç aşamalı bir filtreleme işlemi uygulanmıştır. İlk olarak, çalışma alanının üst ve alt kot seviyeleri, ilk ve son lazer sinyal dönüşlerine göre, düşey profiller çizilerek belirlenmiştir. Daha sonra bir DYM sınıfı oluşturulmuş ve düşey profil seviyeleri arasında kalan tüm noktalar bu sınıfa dahil edilmiştir. Son olarak, bu sınıfın dışında kalan gürültülü noktalar ayrı bir sınıfa dahil edilerek elemine edilmiștir. En doğru DAM ile çıplak topografyayı elde etmek için de yer noktaları benzer şekilde sınıflandırılmış ve gürültü filtrelemesi yapılmıştır. Detaylı filtrelemeye ihtiyaç duyan objelerde alan çevirme ile alan dışı kalan noktalar elemine edilmiştir. Şekil 3, kullanılan filtreleme mantığını anlatan düşey bir ağaç profili örneğini yansıtmaktadır. Örnekte 6 ve 24 m kotlar minimum ve maksimum olarak belirlenmiş ve kot dıșı noktalar elemine edilmiștir.

ALS ve referans TLS nokta bulutlarının konum geometrileri ve yapıları göz önüne alınarak, DYM ve DAM üretimlerinde farklı enterpolasyon teknikleri kullanılmıştır. ALS ve TLS yoğun nokta bulutlarıyla DYM üretimi sırasında önemli bir problem, ağaçlar ve duvarlar gibi düşey nesnelerde ortaya çıkmaktadır. Düşey nesnelerde, yoğun lazer sinyallerine bağlı olarak çok sayıda noktanın kuşbakışı raster model üretiminde aynı piksel içinde kalması o piksele hangi yükseklik değerinin verileceği konusunda probleme yol açmaktadır. Şekil 4, 25 cm'lik örnek piksel için bu problemi yansitmaktadır. $\mathrm{Bu}$ sorun, "Data Metrics" enterpolasyon yöntemi ve maksimum kot değeri kullanımı yardımıyla, piksel içindeki noktaların ortalaması alınmak yerine maksimum nokta yüksekliği kullanılarak așılmıștır. $\mathrm{Bu}$ sayede objelerin maksimum kotlarını kullanan DYM en doğru şekilde edilmiştir. Sadece yer noktaları kullanılarak DAM üretiminde en yakın komşuluk (nearest neighbour) enterpolasyon yöntemi uygulanmıştır. DYM ve DAM üretiminin ardından, sınır hatlarında enterpolasyon etkisini yok etmek için geniş üretilen modeller, çalışma alanının önceden belirlenmiş sınırlarına uyacak şekilde kesilmiştir.

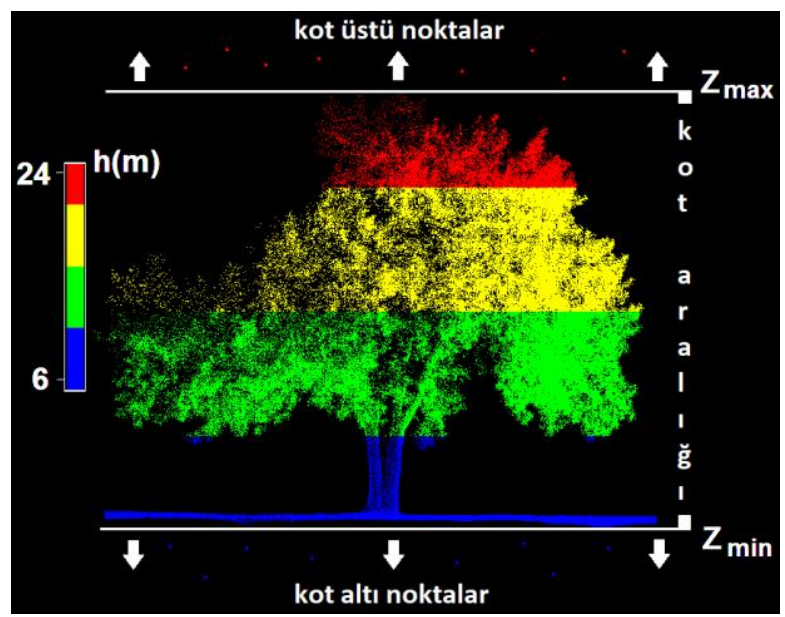

Şekil 3. Gürültü filtreleme mantığı
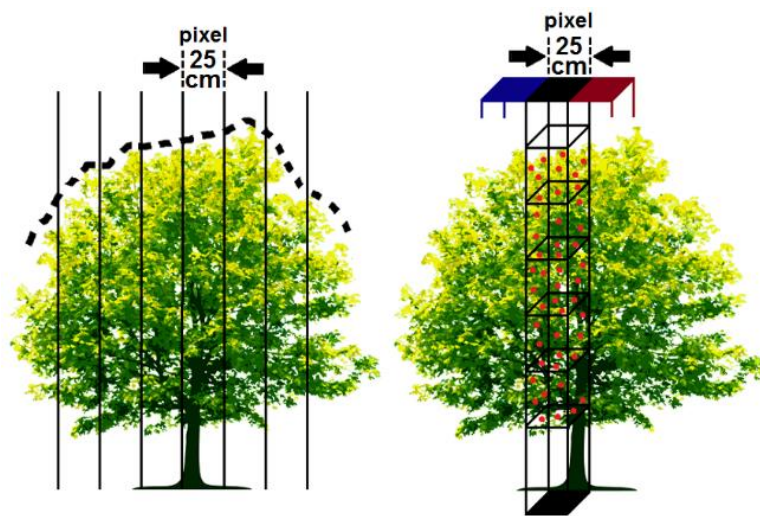

Şekil 4. Düşey objelerde aynı piksel içine fazla sayıda nokta düşmesi sorunu

\subsubsection{B Orman Meşcere Yükseklik Haritası Üretimi}

3B orman meşcere yükseklik haritası, $25 \mathrm{~cm}$ eş gridli elde edilen DYM ve DAM raster modellerinin diferansiyel modeli olan nDYM'nin üretilmesi ve harita bileșenlerinin eklenmesi ile elde edilmiştir. nDYM'nin hesaplanmasında eşitlik 1 kullanılmıştır. 
Temel prensibe göre, çıplak topoğrafya, binaların veya bitki örtüsünün kuşbakışı görünür yüzeylerinden çıarıldığında, geriye kalan nesnenin yüksekliği olacaktır (bakınız Şekil 2).

$$
n D Y M=D Y M-D A M
$$

ALS'de, nDYM, lazer sinyalinin ilk ve son geri yansıdığı yüzeyler arasındaki fark olarak özetlenebilir. Bir nDYM üretiminde dikkat edilmesi gereken en önemli konu, kullanılan DYM ve DAM'ın $\% 100$ yatay örtüşmesidir. Yatay örtüşme sağlanmaması durumunda yataydaki konum farklılığı raster modelde farklı piksellerin diferansiyelinin hesaplanmasına ve hatalı nDYM üretimine sebep olur. Bu çalışmada nDYM'ler, ALS ve TLS nokta bulutlarının her ikisinde de kendi DYM ve DAM'larının \%100 yatay örtüșmesinin sağlanması ardından üretilmișlerdir. Gerçekleștirilen analizlerde DYM ve DAM'larda mm boyutunda yatay kayıklıklar tespit edilmiş ve bu önemsiz düzeydeki kayıklıklar alan bazlı çapraz korelasyon tekniği ile yatay öteleme yöntemi kullanılarak elimine edilmiştir.

\section{3. Üretilen Haritanın Konum Doğruluğu Değerlendirmesi}

Konum doğruluğu değerlendirmesi, uzaktan algılanan verilerden oluşturulan bir haritanın üretiminde ana süreçlerden biridir. Konum doğruluğu, her ölçüm yönteminden beklenen performansa göre harita ölçeği ve veri çözünürlüğü bileșenleri göz önünde tutularak standartlara bağlanmıştır (NDEP, 2004).

Uzaktan algılanan veriler kullanılarak üretilen 3B ürünlerin doğruluğu, genel olarak GNSS ölçümleri ile sahada toplanan yer kontrol noktalarının (YKN) nokta-bazlı konum değerlendirmesi yaklaşımı ile ortaya konmaktadır. Ancak sınırlı sayıda YKN ile yapılan nokta-bazlı değerlendirme, çok yüksek çözünürlüklü ALS nokta bulutları ile oluşturulan 3B sonuç ürünlerin doğruluğunu değerlendirmek için yeterli değildir. Bu yöntem, özellikle ani değişken, eğimli topoğrafyalarda yanıltıcı sayısal sonuçlara ve yorumlara yol açabilmektedir. En güvenilir sonuçlara ulaşmak için, ALS raster haritasının tüm piksellerini doğruluk hesaplamasına dahil eden bir yöntem gereklidir. Bu bağlamda, en uygun teknik, test edilen modelin referans bir modelle model-bazlı karșlaștırmasıdır (Lin ve ark. 1994, Jacobsen 2012). Referans model seçilirken, aşağıdaki kriterler mutlaka göz önünde tutulmalıdır: (i) referans model, dikkate değer bir boşluk yada distorsiyon içermeksizin tüm çalışma alanını kapsamalıdır; (ii) referans modelin çözünürlüğü test edilen modele eşit veya daha yüksek olmalıdır; ve (iii) referans modelin mutlak konum doğruluğu, test edilen modelinkinden üstün olmalıdır. Özellikle (ii) ve (iii) koşulları ve mevcut haritalama teknolojileri göz önünde bulundurularak, oluşturulan ALS 3B meşcere yükseklik haritasının doğruluğunun TLS referans modeli ile değerlendirilmesine karar verilmiştir. TLS nokta bulutları dört bağımsız istasyondan toplanmış ve en az üç harici hedefle dengelenerek geometrik yöneltmeleri yapılmıștır. $\mathrm{Bu}$ hedeflerin hassas konumları $(<5 \mathrm{~mm})$ çift frekanslı GNSS alıcıları kullanılarak, uzun statik ( $>1$ saat) gözlemlerle belirlenmiştir. TLS çoklu geri dönüş sinyali sunan bir tarama teknolojisidir ve bu nedenle, $1 \mathrm{~cm}$ 'lik ortalama nokta aralığı ile bitki örtüsünün tüm seviyelerinden ölçümler elde edilmiştir. Yoğun TLS örnekleme ve çoklu geri dönüş kabiliyeti (bazen giden sinyal başına > 5 geri dönüş), $100 \mathrm{~m}$ mesafede $5 \mathrm{~mm}$ mutlak ve $3 \mathrm{~mm}$ rölatif (bağıl) konum doğruluğu ile meşcerenin tacını modellemeye olanak vermiștir.

Meşcere yükseklik haritasının doğruluk analizleri sırasında Geoid 12A'ya göre $27.284 \mathrm{~m}$ geoid ondülasyonu uygulanmış ve piksel bazlı yükseklik farklılıklarına bağlı mutlak düșey doğruluk, standart sapma (STD) ve normalize medyan mutlak sapma (NMMS) uluslararası standartlarına göre hesaplanmıştır (eşitlik 2 ve 3 ). Arazi eğiminin STD üzerindeki etkilerini görebilmek için, bir arazi eğim fonksiyonu da eşitlik 4'teki şekilde hesaplanmıştır.

$$
\begin{aligned}
& S T D=\sqrt{\frac{\sum_{i=1}^{n}\left(\Delta Z_{i}-\mu\right)^{2}}{n-1}} \\
& N M M S=1.4815 \times \tilde{x}_{i}\left[\left|\Delta Z_{i}-\tilde{x}_{j}\left(\Delta Z_{j}\right)\right|\right] \\
& S T D_{\text {ĕ̆ } \mathrm{im}}=S T D+b \times \tan (\alpha)
\end{aligned}
$$

Eşitlik 2'de $\mu$, analiz edilen model ile referans model arasındaki piksel bazlı yükseklik farklılıklarının $(\Delta Z)$ aritmetik ortalamasını yani sistematik hatayı, $n$ ise karşılaştırılan piksel sayısını ifade etmektedir. Eşitlik 3 'de ise $\widetilde{x}_{j}$, yükseklik farklarının tek değişkenli veri setinin medyanını, $\tilde{x}_{i}$ ise $\tilde{x}_{j}$ 'den gelen yükseklik farklarının medyan değerini ifade eder. Eşitlik 4'te $\alpha$, arazi eğimini ve $b$, eğim çarpanını ifade etmektedir.

NMMS, majör yükseklik farklılıklarının ortaya konması için robust bir doğruluk metriği olmasına rağmen minör yükseklik farklarını ortaya koyma anlamında STD kadar performanslı değildir (Hellerstein 2008). Yükseklik farklılıklarının düzenli dağılımında NMMS ve STD'nin birbirine çok yakın değerde olması ya da NMMS'in daha küçük olması beklenir (Höhle ve Höhle 2009). Doğruluğu değerlendirilen modelde düzensiz hata dağllımına sebep olan bir yapı var ise NMMS değeri STD'den büyük çıkacaktır. Bu durum anormal dağılımı işaret eder ve mutlak düşey doğruluk analizlerinde test edilen modelin rastlantısal majör hatalar içerdiğini gösteren istenmeyen bir durumdur. Böyle bir durumda, 3B modelin üretim teknikleri ve kullanılan parametreler gözden geçirilmelidir. Referans ve analiz edilen modelin diferansiyel yükseklik hata haritaları üretilerek modelin hatalı bölgeleri gözlemlenmeli ve hatalı kısımlardaki hata kaynakları sorgulanmalıdır. Analizde, yükseklik farklılıklarının 
doğrusal bir fonksiyonu olan sistematik hatalar lineer regresyon ile belirlenmiștir. Mutlak düșey doğruluklar, sistematik hatalar düșey öteleme ile elemine edilerek hesaplanmıştır.

\section{BULGULAR}

Şekil 5, ALS yoğun nokta bulutlarından $25 \mathrm{~cm}$ orjinal grid aralıklı olarak üretilmiş DYM ve DAM'ı yükseklik renk skalaları eşliğinde sergilemektedir. Şekilden rahatlıkla görülebileceği gibi ALS DYM oldukça güçlü bir tasvir yeteneğine sahiptir. Yerdeki küçük bitkiler dahi modelde net şekilde görülmektedir. DAM'a bakıldığında ise yoğun orman tabakası altının modellenmesi sırasında ortaya çıkan enterpolasyon etkisi açık şekilde görülmektedir. ALS tekniğinde DAM üretimi için uygulanan teknik lazerin son dönüș sinyallerinden elde edilen yer (ground) noktalarının yalnız bırakılması ve modellenmesidir. Ancak, lazerin son dönüş sinyalleri yoğun orman dokusunda her zaman çıplak topoğrafyaya ulaşmayabilir. Bu nedenle, çalışmanın DAM üretimi ile ilgili bölümünde de vurgulandığı üzere düşey profiller üzerinden filtrelemeler uygulanmış ve gerçek yer noktaları elde edilmiştir. Gerçek yer noktalarının sayısının DYM noktalarına göre oldukça az olmasının sonucunda oluşan boşlukları (gap) doldurmak için enterpolasyona daha çok ihtiyaç duyulmaktadır. Bu durum, çıplak topoğrafyanın modellenme kalitesini objelerin görünür üst yüzeylerinin modellenmesine kıyasla azda olsa düşürmektedir. Açık alanlarda ise nokta yoğunluğunda azalma söz konusu olmadığından enterpolasyon etkisi DYM üretimi ile aynı olacak ve kalite farklılığı ortaya çıkmayacaktır. Şekil 5'te, ALS DYM ve DAM'ının yükseklik skalaları üst kotları incelendiğinde bölgede $20 \mathrm{~m}$ yüksekliğinde ağaçlar bulunduğu yorumu rahatlıkla yapılabilmektedir. Diğer bir çlkarım, ALS DAM'ın yükseklik skalası alt kotları incelendiğinde genel olarak ağaç altı topoğrafyanın arazi ortalamasından daha düşük seviyede olduğudur.

Şekil 6, çalışma alanında arazi ölçümleri ile toplanan TLS verilerinden üretilen ALS ile eş grid aralıklı DYM ve DAM'ı yükseklik renk skalaları eşliğinde göstermektedir. Referans TLS modelleri beklendiği gibi ALS’ye nazaran yakın mesafe ölçümlerinin getirdiği avantajla gerçek topoğrafyanın çok daha yakın bir tasvirini yapmıştır. TLS DAM incelendiğinde ağaç altı topoğrafyanın arazi ortalamasından daha düşük seviyede olduğu çıkarımı doğrulanmıştır.

Şekil 7, NDYM temelinde üretilmiş $25 \mathrm{~cm}$ gridli ALS ve TLS meşcere yükseklik haritalarını, Y yönünde ALS ve TLS meșcere yükseklik haritası düşey profillerini ve ALS-TLS düşey profil karşılaştırma sonuçlarını göstermektedir. Düşey profil örtüşmesi incelendiğinde ALS meşcere yükseklik haritasının tasvir yeteneğinin TLS ile oldukça uyumlu olduğu gözlenmektedir. Tablo 2, ALS yoğun nokta bulutlarından elde edilen DYM, DAM ve meşcere yükseklik haritasının yatay ve düşey mutlak doğruluk değerlerini STD ve NMMS metrikleri cinsinden ortaya koymaktadır.

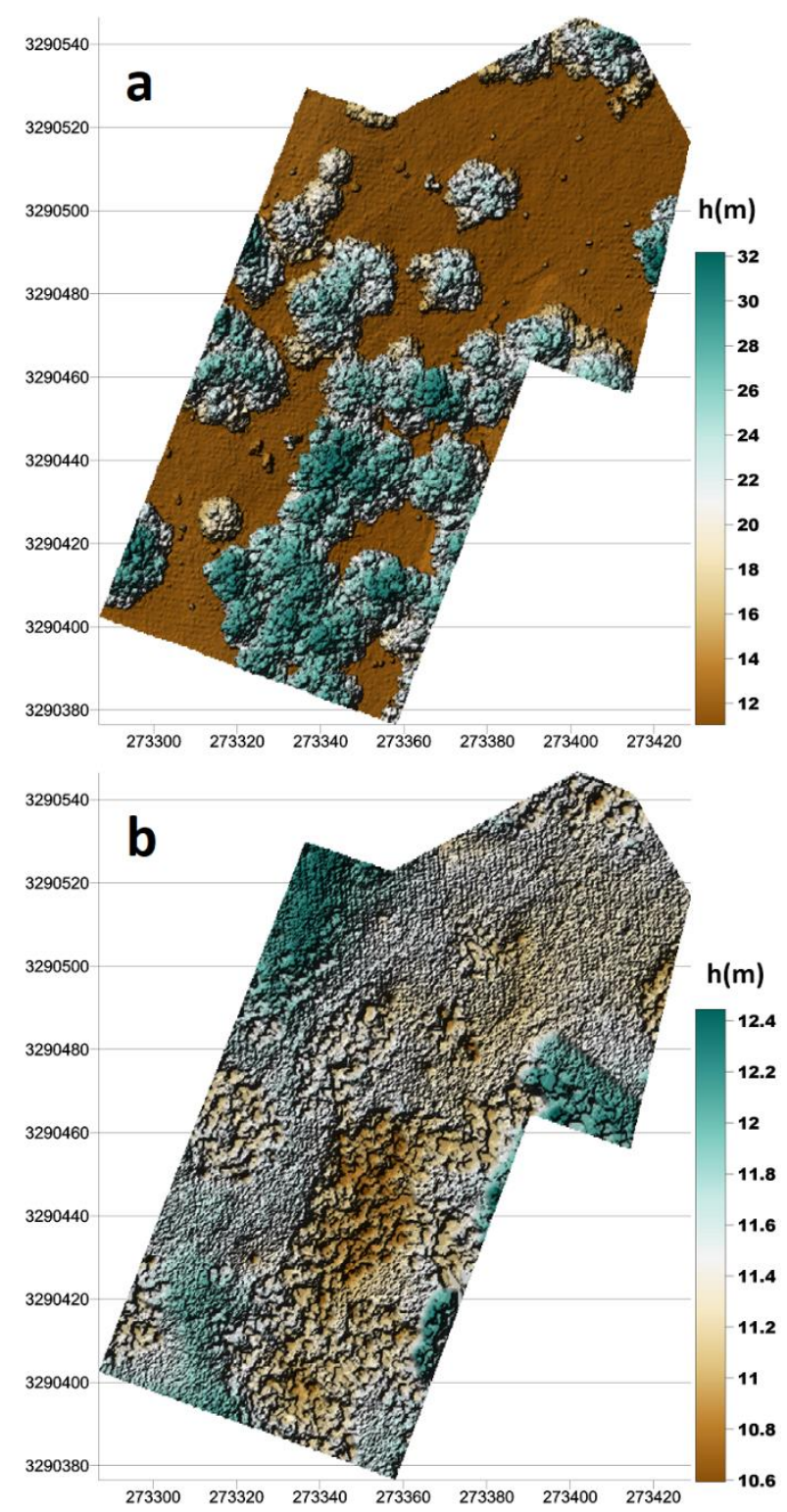

Şekil 5. 25 cm gridli ALS DYM (a) ve DAM (b)

Tablo 2'de yatay mutlak doğruluk değerleri incelendiğinde ALS DYM'nin TLS DYM ile çok iyi uyum sağladığı ancak ALS DAM yatay doğruluğunun $\mathrm{X}$ yönünde $\pm 8 \mathrm{~cm}, \mathrm{Y}$ yönünde yaklașık $\pm 10 \mathrm{~cm}$ mertebesinde olduğu görülmektedir. DAM mutlak yatay doğruluğunun DYM'ye göre daha düşük seviyede olma sebebi üretiminde yalnızca yer noktalarının kullanılması ve filtreleme etkisiyle oluşan boşlukların doldurulması ve boşluksuz raster model elde edilmesi için uygulanan enterpolasyon etkisidir. Enterpolasyon için kullanılan arama yarıçapının (search radius) genişletilme etkisi elde edilen DAM'ın sınır hatlarında bir miktar genișlemeye sebep olmaktadır. İște bu durum, yatay mutlak doğruluk düşüşünde ana etmendir. Unutulmamalıdır ki, enterpolasyon etkisi ne kadar artarsa 3B modelin mutlak konum doğruluğu o kadar olumsuz etkilenecektir. Enterpolasyon işleminin DYM'ler üzerindeki doğruluk kaybı etkisi 
Sefercik ve Alkan 2009'da detaylı olarak sunulmuş ve bu etkinin teoride çözünürlüğün karesi ile doğru orantıll olduğu ortaya konmuștur. Metodoloji bölümünde de belirtildiği üzere, yatayda elde edilen konum farklılıkları düşey analizler gerçekleştirilmeden önce alan bazlı çarpraz korelasyon yöntemi ile ötelenerek elemine edilmiștir.

Tablo 2. ALS DYM, DAM ve meşcere yükseklik haritası yatay ve düșey mutlak doğruluk değerleri

\begin{tabular}{|c|c|c|c|c|c|c|}
\hline $\begin{array}{l}\text { Ref. } \\
\text { model }\end{array}$ & $\begin{array}{c}\text { Test } \\
\text { edilen } \\
\text { model }\end{array}$ & $\begin{array}{r}\operatorname{STD}_{\mathrm{X}} \\
(\mathrm{cm})\end{array}$ & $\begin{array}{r}\mathrm{STD}_{\mathrm{Y}} \\
(\mathrm{cm})\end{array}$ & $\begin{array}{c}\mathrm{STD}_{\mathrm{Z}} \\
(\mathrm{m})\end{array}$ & $\begin{array}{l}\mathrm{STD}_{\mathrm{Z}} \text { eğim } \\
\text { etkili (m) }\end{array}$ & $\begin{array}{c}\text { NMMS } \\
(\mathrm{m})\end{array}$ \\
\hline $\begin{array}{c}\text { TLS } \\
\text { DYM } \\
(0.25 \mathrm{~m})\end{array}$ & $\begin{array}{c}\text { ALS } \\
\text { DYM } \\
(0.25 \mathrm{~m})\end{array}$ & 0.31 & -0.22 & 0.18 & $\begin{array}{c}0.11+0.18 \\
\times \tan (\alpha)\end{array}$ & 0.09 \\
\hline $\begin{array}{c}\text { TLS } \\
\text { DAM } \\
(0.25 \mathrm{~m})\end{array}$ & $\begin{array}{c}\text { ALS } \\
\text { DAM } \\
(0.25 \mathrm{~m})\end{array}$ & 8.02 & 9.61 & 0.14 & $\begin{array}{c}0.18+0.35 \\
\times \tan (\alpha)\end{array}$ & 0.13 \\
\hline TLS & ALS & & & & & \\
\hline $\begin{array}{l}\text { nDYM } \\
(0.25 \mathrm{~m})\end{array}$ & $\begin{array}{l}\text { nDYM } \\
(0.25 \mathrm{~m})\end{array}$ & 0.01 & 0.89 & 0.42 & 0.42 & 0.42 \\
\hline
\end{tabular}
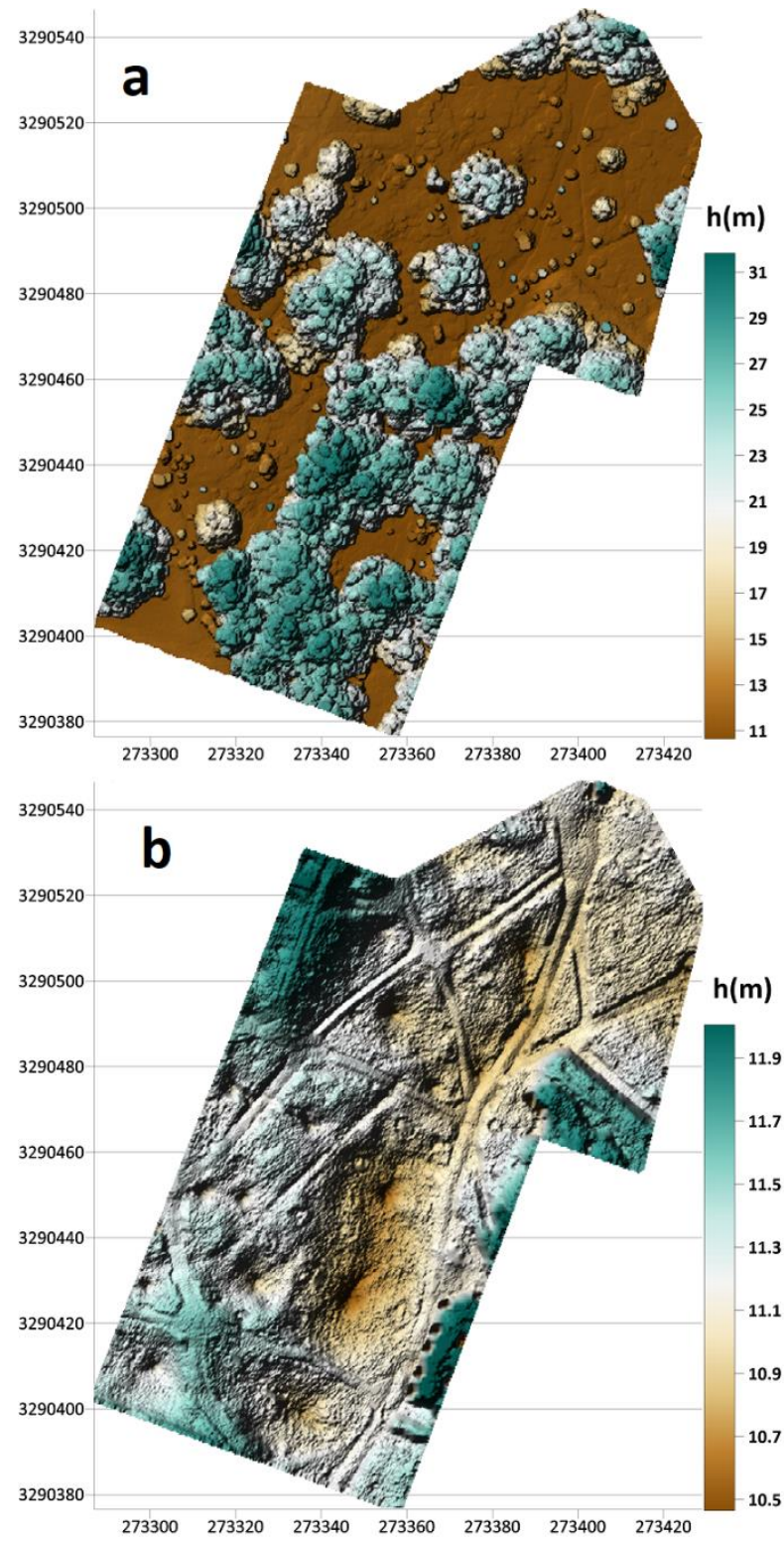

Şekil 6. 25 cm gridli TLS DYM (a) ve DAM (b)
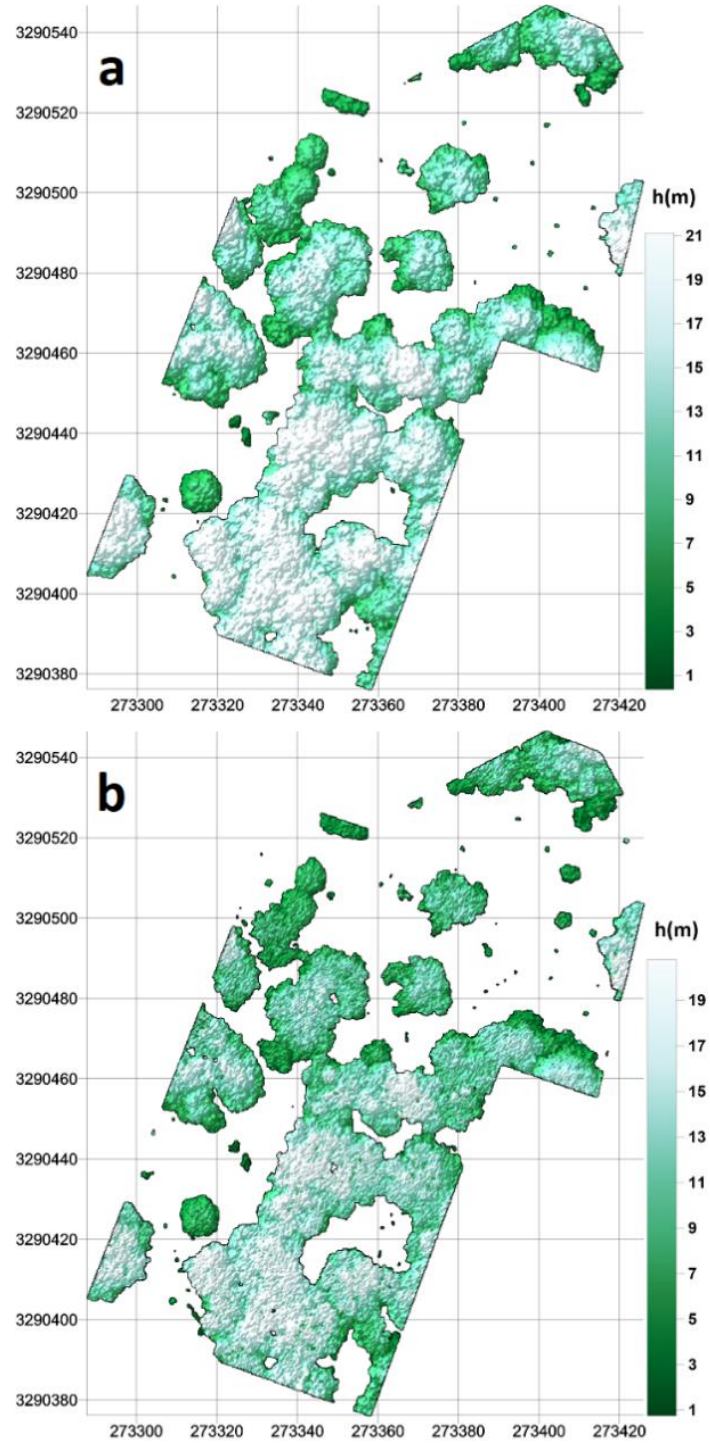

C

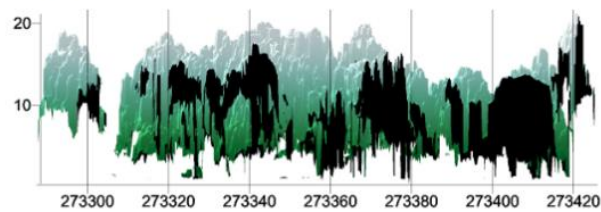

d
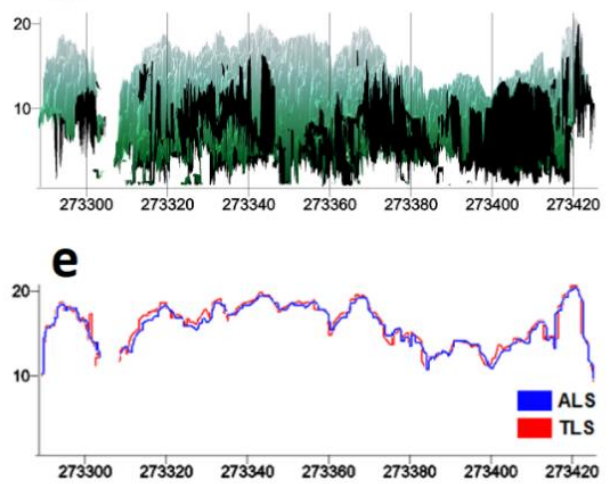

Şekil 7. (a) $25 \mathrm{~cm}$ gridli ALS meşcere yükseklik haritası, (b) $25 \mathrm{~cm}$ gridli referans TLS meșcere yükseklik haritası, (c) Y yönünde ALS meşcere yükseklik haritası düşey profili, (d) Y yönünde referans TLS meșcere yükseklik haritası düșey profili, (e) ALS-TLS düșey profil karșılaștırması 
Tablo 2'de, DYM ve DAM mutlak düşey doğrulukları incelendiğinde majör hatalara duyarlı NMMS değerlerinin STD değerlerinden daha küçük olduğu görülmektedir. Bu durum, ALS ve referans TLS modelleri arasında normal yükseklik farkı dağılımı olduğuna işarettir. NDYM değerlerine bakıldığında ise NMMS ve STD arasında bir eșitlik olduğu görülmektedir. Burada yine olağan dışı (abnormal) bir değişim gözlenmemekle beraber DYM ve DAM değerlerine göre NMMS değerinin STD'ye eşitlenmesi hem majör hem minör yükseklik farklılıklarında ormanın doğruluk düșürücü etki yaptığına işarettir. DYM ve DAM mutlak düssey doğrulukları sırasılyla \pm 18 ve $\pm 14 \mathrm{~cm}$ iken nDYM'de bu değer çıplak topoğrafya ve buna bağlı olarak açık alanların hariç olması nedeniyle yalnızca orman meşceresi etkisi altında $\pm 42 \mathrm{~cm}$ olarak hesaplanmıştr. Şekil 8, ALS nDYM'si ile referans TLS nDYM'si arasındaki piksel bazlı yükseklik farklarının STD ve NMMS metrikleri cinsinden histogramını göstermektedir.

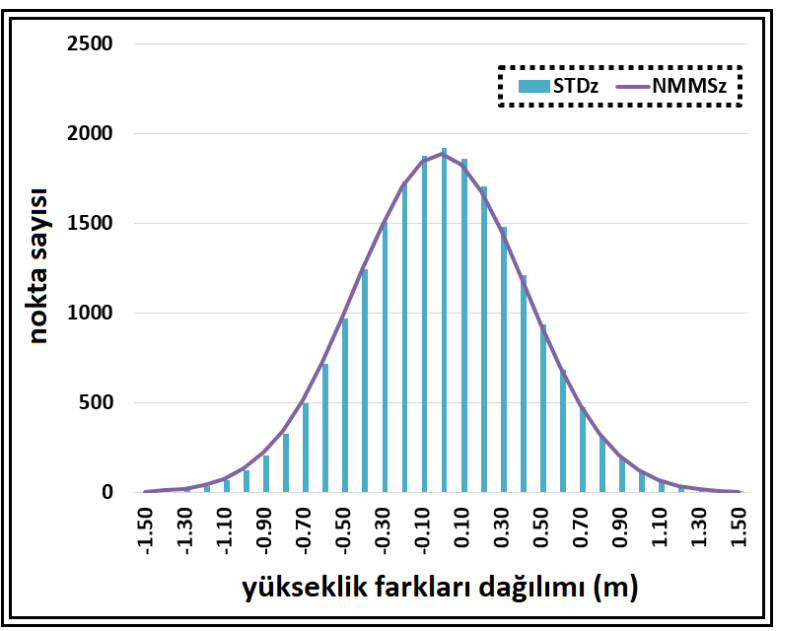

Şekil 8. ALS ve TLS meşcere yükseklik haritası piksel bazlı yükseklik farkları STD ve NMSS dağılımı histogramı

Histogram incelendiğinde, mor renkli NMMS değerleri ve mavi renkle ifade edilen STD değerlerinin her ikisininde modlarının (tepe noktalarının) "0" yükseklik farkında olduğu ve dağılımlarının simetrik olduğu gözlemlenmektedir. Histogramdaki simetrik yapı daha öncede bahsedildiği üzere normal dağılıma işarettir. Her iki histogramda farklı bir doğruluk değerinde yoğunlaşma ve buna bağliikinci bir mod sergilememiştir. $\mathrm{Bu}$ durum, ALS nDYM'sinin herhangi bir distorsiyon ya da olağanüstü hatalı bölge içermediğine işarettir. Histogram ayrıca, piksel bazındaki yükseklik farklarının STD ve NMMS değerlerinin genel itibariyle $\pm 0.5 \mathrm{~m}$ ve altında konumlandığını açık şekilde ortaya koymaktadır.

ALS meşcere yükseklik haritası ile referans TLS haritası arasında piksel yükseklik farklarının yani hataların konumlandığı bölgeleri analiz etmek amacıyla üretilen yükseklik hata haritası Şekil 9'da sunulmuştur. Hata haritası incelendiğinde, hataların haritanın belirli bölgelerinde yoğunlaşmadığı ve rastlantısal şekilde dağılım gösterdiği gözlemlenmiștir. $\mathrm{Bu}$ durum, üretilen haritanın herhangi bir distorsiyon içermediğinin göstergesidir.

Tablo 3. Harita ölçeklerine göre ALS ürünleri yatay ve düssey mutlak konum doğrulukları (KOH: Karesel ortalama hata)(NDEP, 2004)

\begin{tabular}{|c|c|c|c|c|c|}
\hline \multirow[b]{2}{*}{$\begin{array}{l}\text { Harita } \\
\text { ölçeği }\end{array}$} & \multirow{2}{*}{$\begin{array}{l}\text { Kontur } \\
\text { aralığl } \\
\text { (m) }\end{array}$} & \multicolumn{2}{|c|}{ Yatay hata $(\mathrm{m})$} & \multicolumn{2}{|c|}{ Düșey hata (m) } \\
\hline & & $\mathrm{KOH}$ & $\begin{array}{c}\text { STD } \\
(\mathrm{KOH} \sqrt{2})\end{array}$ & $\mathrm{KOH}$ & $\begin{array}{c}\text { STD } \\
(\mathrm{KOH} \sqrt{2})\end{array}$ \\
\hline $1: 1000$ & 1 & 0.56 & 0.40 & 0.30 & 0.21 \\
\hline $1: 2000$ & 2 & 1.12 & 0.79 & 0.61 & 0.43 \\
\hline $1: 5000$ & 5 & 2.79 & 1.97 & 1.52 & 1.07 \\
\hline
\end{tabular}

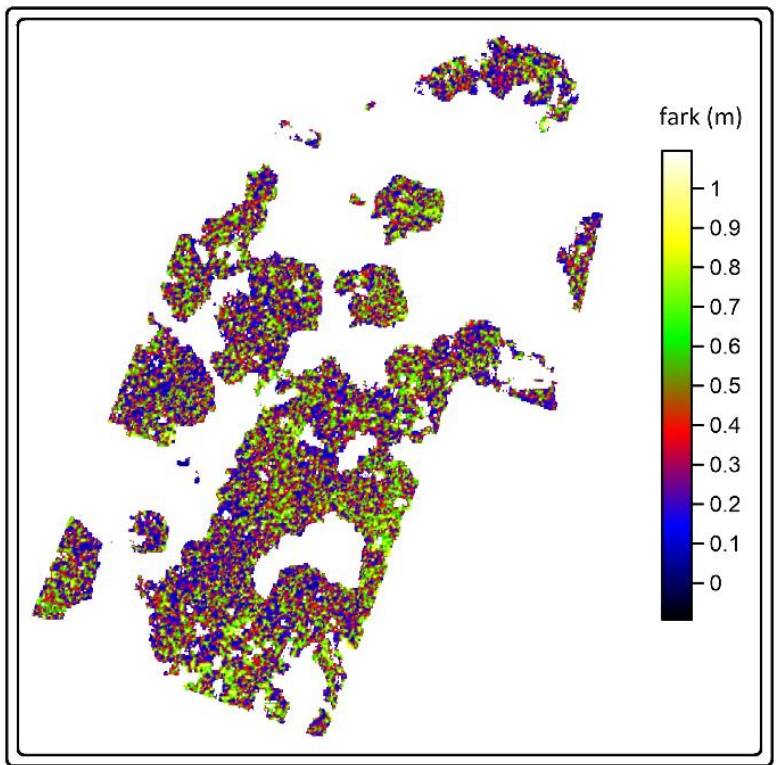

Şekil 9. ALS ve referans TLS meşcere yükseklik haritaları yükseklik hata haritası

\section{TARTISMA}

$\mathrm{Bu}$ bölümde, elde edilen tüm bulguların işaret ettiği nesnel sonuçlar ve ALS verilerinin hangi ölçekte harita üretimine olanak verdiği tartışılmıştır. ALS verilerine ilişkin ülkemizde bir harita ölçeklendirme ilişkisi henüz yayınlanmamış durumda olup bir çok ülke gibi Amerikan Ulusal Dijital Yükseklik Programı (NDEP) tarafından yayınlanmış kriterlere göre yorumlama yapılmaktadır. Tablo 3, NDEP'in 2004 yllında yayınladığı ALS verileri ile harita üretiminde harita ölçeklerine göre aranan yatay ve düşey doğrulukları göstermektedir.

Tablo 3 incelendiğinde üretilen ALS DYM ve DAM'ın yatay ve düşey mutlak konum doğruluklarının (Tablo 2) 1/1000 ölçekli harita üretimine olanak verdiği görülmektedir. Ancak, ağaç altı topoğrafya ve beraberinde açık alanların hariç tutulduğu nDYM temelinde üretilen ALS orman meşcere yükseklik haritasının 1/1000 ölçekli harita doğruluk gereksinimlerini karşılamadığı ve 1/2000 ölçekli harita üretiminde kullanılabileceği belirlenmiștir.

Ülkemizdeki orman haritalarının genelde $1 / 10000$ ve nadiren $1 / 5000$ ölçekte üretilmekte ve kullanılmakta olduğu göz önünde 
bulundurulduğunda ALS verisinin orman haritalamasında çok önemli ve gelişmiş bir çözüm olduğu açıcça kanıtlanmıștır. Ek olarak, orman envanter çalıșmalarının halen yersel ve çoğunlukla kestirime dayalı tekniklerle gerçekleștiriliyor olması havadan orman altı penetrasyon avantajı sunan ve yersel olarak çok uzun zamanlarda elde edilebilecek envanter verilerini çok hızlı elde etmeyi sağlayan ALS tekniğinin bir an önce orman haritalama çalışmalarına dahil edilme gerekliliğini açıkça ortaya koymaktadır.

\section{SONUÇ VE ÖNERÍLER}

Etkin bir uzaktan algılama yöntemi olan ALS, çok yüksek çözünürlüklü, 3B koordinatlı ve yüksek konum doğruluklu nokta bulutları sunmaktadır. Her lazer sinyali başına çoklu ekoların algılanması ve sinyalin penetrasyon yeteneği sayesinde orman örtüsüne nüfuz ederek örtü altı çıplak topoğrafyanın modellenebilmesi tekniğin en büyük avantajlarındandır. $\mathrm{Bu}$ çalışmada, ALS verileri kullanılarak orman-yoğun bir hedef sahada orman meşcere yüksekliğinin 3B haritası üretilmiş ve STD ve NMSS gibi uluslararası kriterlerden faydalanılarak doğruluk değerlendirmeleri yapılmıştır. Doğruluk değerlendirmelerinde hedef sahada gerçekleştirilen TLS ölçümlerinden elde edilen ve nokta yoğunluğu ALS'den katbekat fazla olan veriler ile üretilmiș referans bir harita kullanılmıștır. Uygulamada, geometrik kalibrasyonu tamamlanan ALS verilerinden sırasıyla DYM, DAM ve nDYM üretimleri yapılmıştır.

Bulgular, ALS DYM ve DAM'larının yatay ve düșey mutlak konum doğruluklarının 1/1000 ölçekli harita üretimine olanak verdiğini ortaya koymuştur. nDYM temelinde üretilen ALS orman meşcere yükseklik haritasının ise 1/2000 ölçekli harita üretiminde kullanılabileceği belirlenmiștir. Ülkemizdeki orman haritalarının genelde $1 / 10000$ ve nadiren $1 / 5000$ ölçekte üretilmekte ve kullanılmakta olduğu göz önünde bulundurulduğunda ALS verisinin orman haritalamasında çok önemli ve gelişmiş bir çözüm olduğu açıkça kanıtlanmıștır.

$\mathrm{Bu}$ bulgular ıșığında, \%29'u orman kaplı olan ülkemizde, yersel çalışmalar ile yürütülmeye çalışılan orman envanteri çıkarım faaliyetlerinde ALS'nin mutlaka kullanılması gereken modern bir yöntem olduğu ve doğruluğunun $1 / 5000$ ve 1/10000 ölçekli orman haritalarına göre çok daha yüksek olduğu ortaya çıkmıştır.

\section{TEŞEKKÜR}

Çalışmada kullanılan ALS verilerini sağlayan Houston Üniversitesi Ulusal Hava Kaynaklı Lazer Tarama Merkezi'ne (NCALM) teșekkürlerimizi sunarı.

\section{ARAŞTIRMACILARIN KATKI ORANI}

Umut Güneş Sefercik: Veri toplama, araştırma, analiz, veri ve bulgu yorumlama, makale yazma, düzenleme; Ayhan Ateşoğlu: Araştırma, analiz, veri ve bulgu yorumlama, makale yazma; Can Atalay: Araştırma, düzenleme

\section{ÇATIŞMA BEYANI}

Herhangi bir çıkar çatışması bulunmamaktadır.

\section{KAYNAKÇA}

Akay A E, Wing M, Sessions J (2012) Estimating Structural Properties of Riparian Forests with Airborne LiDAR Data. International Journal of Remote Sensing 33(22): 7010-7023.

Baligh A, Valadan Zoej MJ, Mohammadzadeh A (2008) Bare Earth Extraction from Airborne Lidar Data Using Different Filtering Methods. The International Archives of the Photogrammetry, Remote Sensing and Spatial Information Sciences XXXVII (B3b): 237-240.

Baltsavias E (1999) A Comparison between Photogrammetry and Laser Scanning. ISPRS Journal of Photogrammetry and Remote Sensing 54 (2): 83-94.

Bazezew MN (2017) Integrating airborne lidar and terrestrial laser scanner forest parameters for accurate estimation of above-ground biomass/carbon in Ayer Hitam tropical forest reserve, Malaysia. Doctoral dissertation, University of Twente, Faculty of Geo-Information Science and Earth Observation, Enschede, The Netherlands.

Birdal A C, Avdan U, Türk T (2017). Estimating tree heights with images from an unmanned aerial vehicle. Geomatics, Natural Hazards and Risk 8.2 ,1144-1156.

Glennie C, Carter WE, Shrestha RL, Dietrich WE (2013) Geodetic Imaging with Airborne LiDAR: The Earth's Surface Revealed. Reports on Progress in Physics 76 (8): 086801.

Hauglin M, Lien V, Næsset E, Gobakken T (2014) Georeferencing forest field plots by co-registration of terrestrial and airborne laser scanning data. International Journal of Remote Sensing 35(9): 3135-3149.

Hellerstein J M (2008). Quantitative data cleaning for large databases. Technical Report Presented at United Nations Economic Commission for Europe (UNECE), p. 42.

Hilker T, Van Leeuwen M, Coops NC, Wulder MA, Newnham GJ, Jupp DL, Culvenor DS (2010) Comparing canopy metrics derived from terrestrial and airborne laser scanning in a Douglas-fir dominated forest stand. Trees 24(5): 819-832.

Hill JM, Graham LA, Henry RJ, Cotter DM, Ping A, Young P (2000) Wide-area Topographic Mapping and Applications Using Airborne Light Detection and Ranging (Lidar) Technology. 
Photogrammetric Engineering and Remote Sensing 66 (8): 908-914.

Hollaus M, Wagner W, Maier B, Schadauer K (2007) Airborne Laser Scanning of Forest Stem Volume in a Mountainous Environment. Sensors (Basel) 7(8):1559-1577.

Holopainen M, Kankare V, Vastaranta M, Liang X, Lin Y, Vaaja M, Kukko A (2013) Tree mapping using airborne, terrestrial and mobile laser scanning-A case study in a heterogeneous urban forest. Urban forestry \& urban greening 12(4): 546-553.

Höhle J, Höhle M (2009) Accuracy assessment of digital elevation models by means of robust statistical methods. ISPRS Journal of Photogrammetry and Remote Sensing, 64: 398406.

Hyyppä J, Yu X, Hyyppä H, Matti M (2006) Methods of airborne laser scanning for forest information extraction. Workshop on 3D Remote Sensing in Forestry, 14th-15th Feb 2006, Vienna.

Jacobsen K (2012) Characteristics of Nearly World Wide Available Digital Height Models. 10th Seminar on Remote Sensing and GIS Applications in Forest Engineering, Curitiba, Brazil, October 15-18, p. 8.

Koch B, Heyder U, Welnacker H (2006) Detection of individual tree crowns in airborne LiDAR data. Photogrammetric Engineering and Remote Sensing 72: 357-363.

Liang X, Kankare V, Hyyppä J, Wang Y, Kukko A, Haggren H, Yu X, Kaartinen H, Jaakkola A, Guan F, Holopainen M, Vastaranta M (2016) Terrestrial laser scanning in forest inventories. ISPRS Journal of Photogrammetry and Remote Sensing 115: 63-77.

Lin Q, Vesecky JF, Zebker HA (1994) Comparison of Elevation Derived from Insar Data with DEM over Large Relief Terrain. International Journal of Remote Sensing 15 (9): 1775-1790.

Liu X, (2008) Airborne LiDAR for DEM Generation: Some Critical Issues. Progress in Physical Geography 32: 31-49.

Lohr U (1998) Digital Elevation Models by Laser Scanning. The Photogrammetric Record 16 (91): 105-109.

Ma L, Zheng G, Eitel JU, Magney TS, Moskal LM (2017) Retrieving forest canopy extinction coefficient from terrestrial and airborne lidar. Agricultural and Forest Meteorology 236: 1-21.

Mandlburger G, Briese C, Pfeifer N (2007) Progress in LiDAR Sensor Technology- Chance and Challenge for DTM Generation and Data Administration. In: D. Fritz (Ed.): Proceedings of 51st Photogrammetric Week '07, Wichmann Verlag, Hiedelberg, pp. 159-169.

McIntosh K, Krupnik A, Schenk A (2000) Improvement of Automatic DSM Generation over
Urban Areas Using Airborne Laser Scanner Data. International Archives of Photogrammetry and Remote Sensing XXXIII (B3): 563-570.

NDEP (2004) Guidelines for Digital Elevation Data. https://files.nc.gov/ncdit/documents/files/NDE P-Elevation-Guidelines-Ver1-10May2004.pdf

Paris C, Kelbe D, Van Aardt J, Bruzzone L (2017) A novel automatic method for the fusion of ALS and TLS LiDAR data for robust assessment of tree crown structure. IEEE Transactions on Geoscience and Remote Sensing 55(7): 36793693.

Sefercik UG, Alkan M (2009) Advanced Analysis of Differences Between C and X Bands Using SRTM Data for Mountainous Topography. Journal of the Indian Society of Remote Sensing, 37(3): 335349.

Sefercik UG, Glennie C, Singhania A, Hauser D (2015) Area-based quality control of airborne laser scanning 3D models for different land classes using terrestrial laser scanning: sample survey in Houston, USA. Int J Remote Sens 36(23):59165934.

Shan J, Sampath A (2005) Urban DEM Generation from Raw Lidar Data: A Labeling Algorithm and Its Performance. Photogrammetric Engineering \& Remote Sensing 71 (2): 217-226

Smreček R (2012) Utilization of ALS data for forestry purposes. In: T. Jekel, A. Car, J. Strobl and G. Griesebner (Ed.): GI Forum 2012: Geovizualisation, Society and Learning, ISBN 978-3-87907-521-8, pp. 365-375.

Stereńczak K, Będkowski K, Weinacker H (2008) Accuracy of crown segmentation and estimation of selected trees and forest stand parameters in order to resolution of used DSM and nDSM models generated from dense small footprint LIDAR data. International Archives of Photogrammetry and Remote Sensing 37 (B6b): 27-32.

Şanlıoğlu İ, Zeybek M, Karauğuz G (2013) Photogrammetric Survey And 3d Modeling of Ivrız Rock Relıef In Late Hittite Era. Mediterranean Archaeology \& Archaeometry 13.2.

Vatandaşlar C, Zeybek M. (2020) Application of handheld laser scanning technology for forest inventory purposes in the NE Turkey. Turkish Journal of Agriculture and Forestry: 44.

Vosselman G, Maas H G (2010) Airborne and Terrestrial Laser Scanning. Whittles Publishing. 318 pages.

Zeybek M, Şanlığlu İ (2015). Accurate determination of the Taşkent (Konya, Turkey) landslide using a long-range terrestrial laser scanner. Bulletin of Engineering Geology and the Environment 74.1 (2015): 61-76. 